\title{
Low levels of soluble CD1d protein alters NKT cell function in patients with rheumatoid arthritis
}

\author{
SEIJI SEGAWA, DAISUKE GOTO, YOHEI YOSHIGA, TAICHI HAYASHI, \\ ISAO MATSUMOTO, SATOSHI ITO and TAKAYUKI SUMIDA \\ Division of Clinical Immunology, Doctoral Program in Clinical Sciences, \\ Graduate School of Comprehensive Human Sciences, University of Tsukuba, Japan
}

Received April 6, 2009; Accepted May 15, 2009

DOI: 10.3892/ijmm_00000256

\begin{abstract}
CD1d molecules on the cell surface play a critical role in the presentation of glycolipid antigens to natural killer $\mathrm{T}$ (NKT) cells. We previously showed that the human CD1d gene has 8 splice variants, one of which is a soluble form lacking the $32-\mathrm{m}$ and transmembrane domains. This study focused on soluble CD1d (sCD1d) by generating recombinant sCD1d proteins and assaying them in plasma using a newly established ELISA method. The amount of sCD1d proteins in plasma was significantly decreased in rheumatoid arthritis (RA) patients $(55.2 \pm 13.3$ years, mean \pm SD) compared with healthy donors (31.2 \pm 7.4 years). Plasma sCD1d protein levels correlated with the number of NKT cells (TCR $\left.\mathrm{V} \alpha 24^{+} \mathrm{VB} 11^{+} \mathrm{CD}^{+}\right)$in peripheral blood mononuclear cells $\left(\mathrm{r}^{2}=0.061\right)$. Furthermore, sCD1d proteins induced IFN- $\gamma$ production from NKT cells, but neither IL-4 nor IL-10. These findings suggest that the low plasma levels of sCD1d protein in RA patients reduce the number and thus activation of peripheral NKT cells. It is therefore hypothesized that sCD1d stimulates NKT cells and low plasma sCD1d levels in RA reflect a pathogenic mechanism associated with a decrease in NKT cells.
\end{abstract}

Correspondence to: Professor Takayuki Sumida, Division of Clinical Immunology, Doctoral Program in Clinical Sciences, Graduate School of Comprehensive Human Sciences, University of Tsukuba, 1-1-1, Tennoudai, Tsukuba, Ibaraki, 305-8575, Japan

E-mail: tsumida@md.tsukuba.ac.jp

Abbreviations: APC, antigen-presenting cell; $\alpha$-GalCer, $\alpha$-galactosylceramide; CIA, collagen-induced arthritis; ELISA, enzyme-linked immunosorbent assay; FBS, fetal bovine serum; IFN, interferon; IL, interleukin; $\mathrm{mAb}$, monoclonal antibody; $\mathrm{MHC}$, major histocompatibility complex; NKT, natural killer T; PBS, phosphate-buffered saline; RA, rheumatoid arthritis; rh, recombinant human; sCD1d, soluble CD1d; SD, standard deviation; TCR, T cell receptor; Th, T helper; ß2-m, ß2-microglobulin

Key words: natural killer T cells, autoimmune disease, rheumatoid arthritis, CD1d, soluble CD1d, rheumatoid arthritis

\section{Introduction}

The CD1 family of molecules comprises nonpolymorphic major histocompatibility complex (MHC) class I-like proteins (1-3), characterized by a $43-49-\mathrm{kDa}$ heavy chain in noncovalent association with a $12-\mathrm{kDa}$ 32-microglobulin (ß2-m) light chain. CD1 genes map to chromosome 1q22-23 (4) and are classified into two groups based on sequence homology, group 1 (CD1a, 1b, 1c, and 1e) and group 2 (CD1d) $(5,6)$. Group $1 \mathrm{CD} 1$ molecules mainly present lipid antigens to clonally diverse $\mathrm{T}$ cells to mediate adaptive immunity against a vast range of microbial lipid antigens. In contrast, CD1d (group 2) molecules are expressed on the surface of cortical thymocytes (7), B cells (8), dendritic cells (9-11), Langerhan's cells in the skin (12), and gastrointestinal epithelial cells $(9,11)$. The soluble form of CD1d (sCD1d) presents glycolipid antigens to natural killer T (NKT) cells.

NKT cells express the surface marker, NKR-P1A (CD161), and a highly restricted T-cell antigen receptor (TCR) comprised of an invariant $\operatorname{TCR} \alpha$ chain with a single rearrangement (TCR V $\alpha 14-\mathrm{J} \alpha 18$ in mice, and TCR V $\alpha 24-\mathrm{J} \alpha 18$ in humans) (13) coupled with TCRß chains with limited heterogeneity due to marked skewing of TCR Vß gene usage (mostly TCR Vß8.2 in mice and TCR Vß11 in humans) (14). NKT cells recognize glycosphingolipid $\alpha$-galactosylceramide ( $\alpha$-GalCer), bind to CD1d, and respond by secreting a variety of cytokines, including Th1 cytokines such as IL-2 and IFN- $\gamma$, and Th2 cytokines such as IL-4 and IL-10 in humans or IL-17 in mice (15). This ability to potently modulate adaptive immunity upon stimulation of a restricted set of antigen-specific receptors, together with a lack of immunological memory, closely resembles the properties of cell types belonging to the innate immune system (16).

Human NKT cells are believed to regulate immune tolerance or autoimmunity (17). Indeed, the NKT cell number is selectively decreased in human autoimmune diseases, such as rheumatoid arthritis (RA), systemic sclerosis, systemic lupus erythematosus, Sjögren's syndrome, and type I diabetes mellitus (18-20).

We previously identified alternatively spliced variants of human CD1d mRNA in peripheral blood mononuclear cells (PBMCs) (21). Two of these, V1 and V2, were considered functional due to complete conservation of the antigen-binding site. V1 lacks exon 4 (ß2-m binding domain) of the CD1d gene, resulting in unstable antigen presentation, while V2 lacks both 
exon 4 and 5 (transmembrane domain), resulting in sCD1d. The expression levels of sCD1d mRNA were significantly lower in RA patients than healthy donors, although there was no significant difference in the number of intact $\mathrm{CD} 1 \mathrm{~d}^{+}$cells in peripheral blood (22). The functional relevance of sCD1d protein, which is present in plasma, remains unclear. The present study was designed to determine the plasma sCD1d levels by developing a new two-sites enzyme-linked immunosorbent assay (ELISA) detection system. Preliminary testing with this method showed significantly low plasma sCD1d protein and sCD1d mRNA levels in PBMCs of RA patients compared with those of healthy donors. In addition, plasma levels of sCD1d protein correlated with the proportion of NKT cells among PBMCs. These findings implicate a role for sCD1d in stimulating NKT cell production. The relevant effects in RA are also discussed.

\section{Materials and methods}

Patients and healthy donors. We examined 52 patients with RA (age 55.2 \pm 13.3 years, mean $\pm \mathrm{SD}$ ) diagnosed according to the criteria of the American College of Rheumatology (ACR; formerly, the American Rheumatism Association). All patients and 40 disease-free healthy donors $(31.2 \pm 7.4$ years of age $)$ were referred to the University of Tsukuba Hospital and gave their written consent for this study. The study was approved by the ethics committee of the university of Tsukuba Hospital.

Plasma and PBMC samples. The PBMCs of patients and healthy donors were isolated using Ficoll-Paque (GE Healthcare UK, Little Chalfont, UK) density-gradient centrifugation. The supernatant was recovered as plasma, and the pelleted PBMC fraction was ready for use after washing twice with phosphate-buffered saline (PBS).

Polyclonal antibody specific for $s C D 1 d$. Rabbits were injected every 2 weeks for a total of 5 times with sCD1d-specific C-terminal 14-mer (QDLWTSGSQDFSPG) peptides linked to a carrier protein (KLH). Whole blood was collected and the serum obtained.

Constructs and reagents. V1 CD1d and sCD1d cDNA were obtained from PBMCs as described previously (22). The PCR-products were subsequently digested with HindIII-NotI and cloned into pcDNA3.1 (Invitrogen, San Diego, CA), resulting in pcDNA3.1-sCD1d, -V1 CD1d, and -mock as a control. The cloned PCR-fragments were sequenced in both directions according to a standard protocol (ABI PRISM BigDye Terminator Cycle Sequencing Ready Reaction Kit) and analyzed using an ABI PRISM 310 Genetic Analyzer (Applied Biosystems, Framingham, PA).

Production and purification of soluble CD1d proteins. Cos-7 cells $\left(5 \times 10^{5}\right)$ were grown on $10-\mathrm{cm}$ tissue culture dishes (TPP) in Dulbecco's modified Eagle's medium supplemented with $10 \%$ fetal bovine serum (BioWest, FL) and $1 \%$ penicillin/ streptomycin (Invitrogen) at $37^{\circ} \mathrm{C}$ with $5 \% \mathrm{CO}_{2}$. Plasmid DNA was transfected into Cos-7 cells using FuGeneHD transfection reagents (Roche, Basel, Switzerland), and the cells were cultured for $24 \mathrm{~h}$ before rinsing in PBS and lysis in the following buffer, $50 \mathrm{mM} \mathrm{Na}_{2} \mathrm{PO}_{4}, 300 \mathrm{mM} \mathrm{NaCl}, 0.5 \% \mathrm{NP}-40$, and $2 \mathrm{mM}$ phenylmethylsulfonyl fluoride (PMSF), $\mathrm{pH}$ 7.4. The supernatant obtained after centrifugation at $10,000 \mathrm{x}$ g was used as purification sample.

Proteins were then purified using HiTrap NHS-activated HP affinity columns (GE Healthcare) according to the instructions provided by the manufacturer. The FLAG column prepared above was used for immunoaffinity purification of FLAG M2 antibody (Sigma, St. Louis, MO). The column was washed sequentially with start buffer $(10 \mathrm{mM}$ Tris-HC1, $\mathrm{pH} 7.5)$ and elution buffer (100 mM glycine, $\mathrm{pH} 2.5)$, and was finally equilibrated with start buffer. Purified samples were loaded onto the column. Bound proteins were eluted with $0.1 \mathrm{M}$ glycine, $\mathrm{pH} 2.5$, and the $\mathrm{pH}$ was brought to neutral by adding 0.1 volume of neutralizing buffer (1 M Tris-HC1, $\mathrm{pH} 8.0)$. After elution, the samples were concentrated and dialyzed against PBS using an Amicon Ultra with a $10-\mathrm{kDa}$ cut-off (Millipore, Billerica, MA).

Immunoprecipitation and immunoblotting. sCD1d-transfected cells were lysed and subjected to immunoblotting (blot). Aliquots of the lysates were separated by SDS-polyacrylamide gel electrophoresis (SDS-PAGE) and transferred to membranes (Bio-Rad, Hercules, CA). The membranes were subjected to blotting with anti-FLAG antibodies. The culture supernatants of sCD1d-transfected cells were subjected to immunoprecipitation (IP) with anti-CD1d monoclonal antibodies followed by adsorption to protein G Sepharose (Pharmacia Biotech, Uppsala, Sweden). The precipitates were immunoblotted with anti-FLAG antibodies.

Specific ELISA assay systems for soluble CDId. A two-sites ELISA assay was established to detect and measure sCD1d. Anti-human CD1d monoclonal antibody (mAb; $0.1 \mu \mathrm{g} / \mathrm{ml}$, Santa Cruz Biotechnology, Santa Cruz, CA) in PBS was added to wells of a plate (Nunc, Roskilde, Denmark) and incubated overnight at $4{ }^{\circ} \mathrm{C}$. The wells were washed three times with a wash buffer $(0.05 \%$ Tween-20 in PBS), and then blocked with commercial blocking buffer (Dainippon Sumitomo Seiyaku, Osaka, Japan) for $2 \mathrm{~h}$ at $37^{\circ} \mathrm{C}$. We then added $100 \mu \mathrm{l}$ of a plasma sample diluted 1:5 in PBS and incubated overnight at room temperature. After washing three times with wash buffer, $100 \mu \mathrm{l}$ of anti-sCD1d polyclonal antibody (prepared in-house) diluted to $1: 1,000$ in PBS was added to each well and incubated for $4 \mathrm{~h}$ at $37^{\circ} \mathrm{C}$. After washing three times with wash buffer, $100 \mu 1$ of horseradish peroxidase (HRP)-labeled anti-rabbit antibody (Santa Cruz Biotechnology) diluted $1: 3,000$ in PBS, was added to each well, and incubated for $2 \mathrm{~h}$ at $37^{\circ} \mathrm{C}$. After final washing (6 times) with the wash buffer, $100 \mu 1$ of substrate (Pierce, Rockford, IL) was added to each well, and left for $90 \mathrm{~min}$. The optical density (OD) of each well was measured at $405 \mathrm{~nm}$ using a microplate reader (Bio-Rad).

Staining and flow cytometry. Fluorescein isothiocyanate (FITC)-labeled anti-TCR V $\alpha 24$ and phycoerythrin (PE)labeled anti-TCR VB11 monoclonal antibodies were purchased from Beckmann Coulter (Fullerton, CA). The allophycocyanin (APC)-conjugated anti-CD3 monoclonal antibody (mAb) was obtained from BioLegend (San Diego, CA). The frequency of invariant NKT cells was estimated using three-color anti-TCR 
Va24/anti-TCR Vß11/anti-CD3 staining. The stained cells were analyzed on a CyAn ADP (DAKO, Glostrup, Denmark) and data were processed using Summit4.3 (DAKO).

Preparation of antigen presenting cells. PBMCs were isolated using Ficoll-Paque (GE Bioscience) density gradient centrifugation, and $\mathrm{CD} 14^{+}$monocytes were harvested from the PBMCs using a MACS system (Miltenyi Biotec, Bergisch Gladbach, Germany). The $\mathrm{CD} 14^{+}$monocytes were cultured for 6 days in complete RPMI 1640 (supplemented with $10 \%$ heat-inactivated fetal bovine serum (BioWest), $1 \%$ penicillin/ streptomycin, $10 \mathrm{mM} \mathrm{N}$-2-hydroxyetylpiperazine-N'-ethanesulphonic acid (HEPES)-NaOH, $0.1 \mathrm{mM}$ minimum essential medium (MEM) nonessential amino acids, $1 \mathrm{mM}$ sodium pyruvate, and $5.5 \mu \mathrm{M}$ 2-mercaptoethanol (Invitrogen) in the presence of $50 \mathrm{ng} / \mathrm{ml}$ recombinant human granulocytemonocyte colony-stimulating factor (GM-CSF) and $100 \mathrm{ng} / \mathrm{ml}$ recombinant human IL-4 (R\&D Systems, Minneapolis, IL) to obtain human monocyte-derived dendritic cells (Mo-DCs).

Expansion and sorting of TCR Va24+ Vß11+ NKT cells. PBMCs were isolated using Ficoll-Paque (GE Bioscience) density gradient centrifugation and cultured with $100 \mathrm{ng} / \mathrm{ml} \alpha$-galactosylceramide ( $\alpha$-GalCer, Krin Brewery, Gunma, Japan) and $100 \mathrm{ng} / \mathrm{ml}$ recombinant human IL-2 (rhIL-2, MBL, Woburn, MA) at a density of $10^{6}$ cells $/ \mathrm{ml}$ complete RPMI 1640. After 7 days, cells were restimulated with $\alpha$-GalCer-pulsed Mo-DCs and co-cultured with $100 \mathrm{ng} / \mathrm{ml} \mathrm{rhIL}-2$. On day 7 after restimulation, $\mathrm{V} \alpha 24^{+}$cells were isolated using a MACS system (Miltenyi Biotec). These isolated cells were then again restimulated with $\alpha$-GalCer pulsed Mo-DCs and co-cultured with $100 \mathrm{ng} / \mathrm{ml} \mathrm{rhIL}-2$. The expanded NKT cells were stained with FITC-labeled anti-TCR Va24 mAb, PE-labeled anti-TCR $\mathrm{VB1} 1 \mathrm{mAb}$ and APC-labeled anti-CD3 mAb. The CD3 ${ }^{+}, \mathrm{Va}_{2} 4^{+}$, $\mathrm{V} ß 11^{+}$lymphocyte-gated cells were sorted on a MoFlo cell sorter (DAKO).

Stimulation of TCR Va24+ Vß11 $1^{+}$NKT cells by plate-bound $C D 1 d$ dimer or $s C D 1 d$ protein. Multiwell Plates were coated with CD1d dimer XI ( $1 \mu \mathrm{g}$ in $100 \mu \mathrm{l} \mathrm{PBS} /$ well), purified sCD1d protein, or mock protein for $16 \mathrm{~h}$. After washing with PBS, $\alpha$-GalCer was added $(0.1 \mathrm{ng} / \mu 1$ in PBS/well) and incubated at $37^{\circ} \mathrm{C}$ for another $24 \mathrm{~h}$. NKT cells were then added to the wells and cytokine production analyzed after a further $72 \mathrm{~h}$.

Measurement of cytokines. The cytokine levels in the culture supernatants were evaluated by ELISA (R\&D Systems).

Statistical analysis. Data are expressed as a median and mean \pm SD. Data were analyzed using a statistical software package (Stat View 5.0, SAS Institute, NC). Differences between groups were examined for statistical significance using the MannWhitney U-test and Spearman's rank correlation. A P-value $<0.05$ denoted the presence of a statistically significant difference.

\section{Results}

Soluble CDIds are expressed intra- and extracellularly. We reported previously the expression of sCD1d mRNA in PBMCs
A
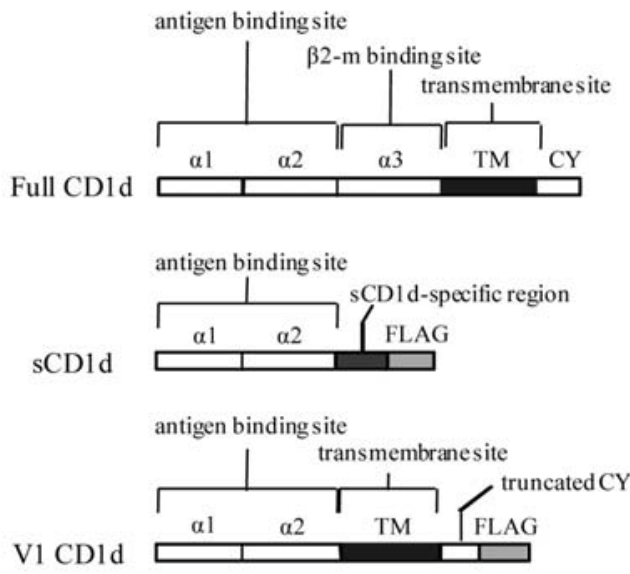

B

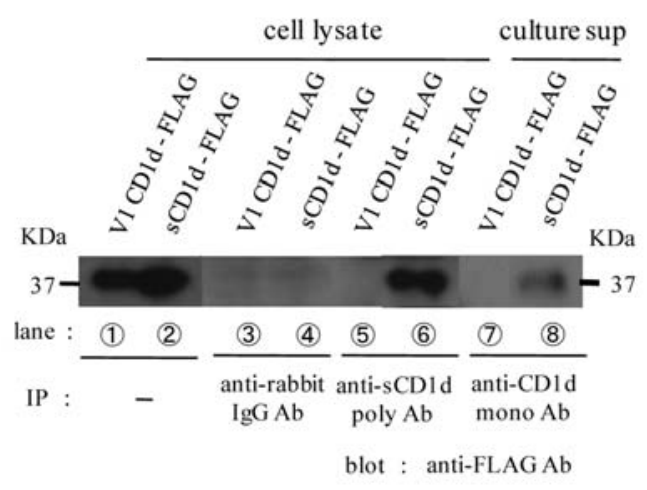

Figure 1. Expression of recombinant variant CD1d proteins. (A) Recombinant proteins of sCD1d and V1 CD1d were cloned into expression vectors, with FLAG tags expressed at the C-terminus for purification and detection. (B) Cos-7 cells were transfected to express V1 CD1d and sCD1d. After incubation for $24 \mathrm{~h}$, cells were harvested to analyze the expression using anti-sCD1d polyclonal antibodies. We performed immunoprecipitation (IP) and immunoblotting (blot) analysis as indicated. Lanes 1-2, positive control; lanes 3-4, negative control; lanes 5-6, anti-sCD1d polyclonal antibodies specific for sCD1d protein; lanes $7-8$. The secreted recombinant sCD1d was also detected in the Cos-7 cell culture supernatant. Only sCD1d molecules were detected and not other CD1d variant (V1) proteins.

(21). sCD1ds are characterized by defective alignment of the B2-m binding and transmembrane domains, compared to other family members (21) (Fig. 1A). To examine whether sCD1d proteins are secreted, we expressed recombinant FLAG-tagged sCD1d in Cos-7 cells. Culture supernatants were immunoprecipitated using anti-CD1d monoclonal antibodies, and bound proteins detected by immunoblotting with anti-FLAG antibodies (Fig. 1B). The sCD1d protein was present in culture supernatants, although the V1 was not detected. V1 CD1d is considered insoluble, because the transmembrane domain unique to CD1d is completely conserved (Fig. 1A). These results indicate that $\mathrm{sCD} 1 \mathrm{~d}$ protein is secreted extracellularly and it is likely that the same mechanism applies in vivo. 
A

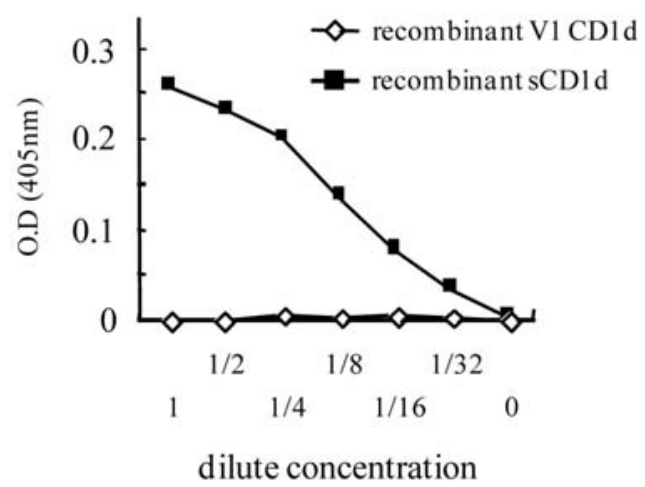

B

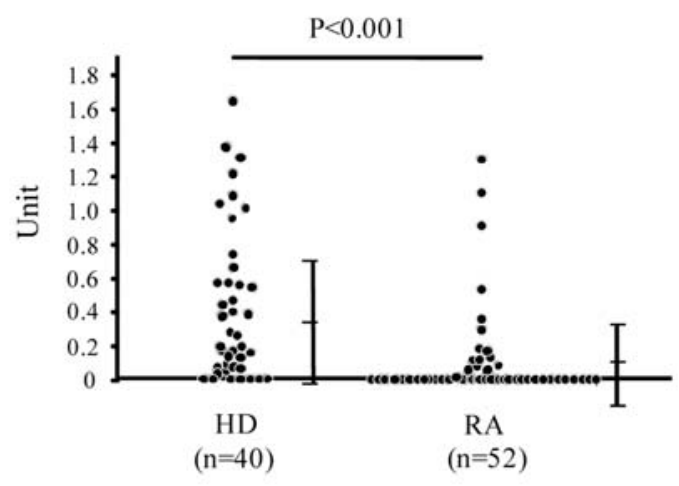

Figure 2. Establishment of sCD1d-specific ELISA using anti-CD1d monoclonal and anti-sCD1d polyclonal antibodies to reveal low sCD1d proteins in RA patients. (A) Purified recombinant V1 CD1d and sCD1d proteins as specifically measured by the developed ELISA system. (B) The levels of sCD1d proteins in plasma of healthy donors $(n=40)$ and RA patients $(n=52)$ determined by the sCD1d-specific ELISA. The level of secreted sCD1d protein in RA patients $(0.10 \pm 0.29 \mathrm{U} / \mathrm{ml})$ was significantly lower than in healthy donors $(0.39 \pm 0.42 \mathrm{U} / \mathrm{ml})$. Each point represents the sCD1d ratio (unit) from a specific healthy control. Comparison of median between different groups was performed using the Mann-Whitney $\mathrm{U}$ test.

Patients with RA have low plasma levels of sCDId. To examine the levels of sCD1d proteins in the peripheral blood of patients with RA, we established the sCD1d-specific ELISA. The specificity of sCD1d binding was confirmed by recombinant $\mathrm{sCD} 1 \mathrm{~d}$ and $\mathrm{V} 1 \mathrm{CD} 1 \mathrm{~d}$ proteins (Fig. 2A). Preliminary experiments indicated that detection of sCD1d protein was more sensitive in plasma compared with serum (data not shown). Therefore, plasma samples from 52 RA patients and 40 healthy donors were tested. The sCD1d protein concentrations in plasma samples of RA patients $(0.10 \pm 0.29 \mathrm{U} / \mathrm{ml})$ were significantly lower than those of healthy controls $(0.39 \pm 0.42 \mathrm{U} / \mathrm{ml})$ (Fig. 2B). Though there was a significant difference in age between healthy donors and RA patients, we confirmed age had no influence on sCD1d expression in plasma (data not shown).

Plasma levels of sCDId protein correlated with number of TCR Va $24^{+} V \beta 11^{+}$NKT cells. We also determined the proportion of NKT cells in PBMCs from the same set of plasma samples.
A

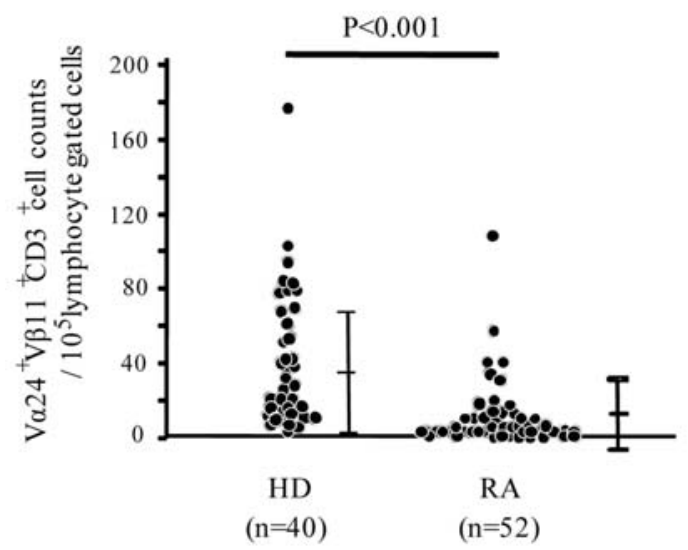

B

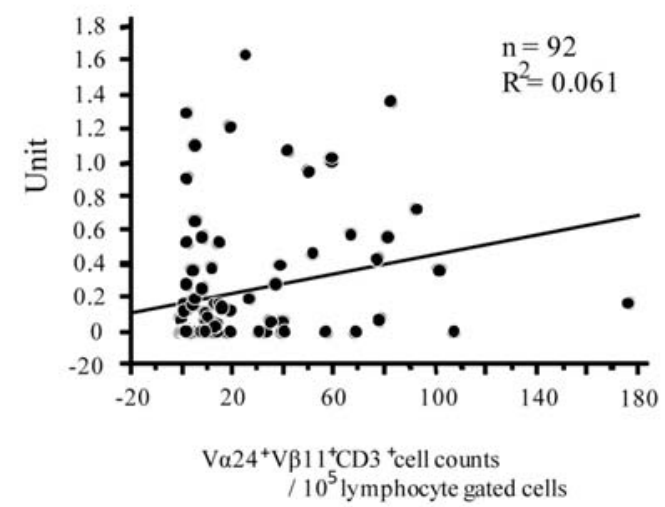

Figure 3. Correlation between sCD1d protein in plasma and NKT cells in PBMCs. (A) NKT cells among PBMCs from healthy donors $(n=40)$ and RA patients $(n=52)$ were stained with monoclonal antibodies, FITC-labeled antiTCR Va24 mAb, PE-labeled anti-TCR VB11 mAb, and APC-labeled antiCD3 mAb. The number of NKT cells in $10^{5}$ PBMCs was counted. NKT cells were significantly fewer in number in RA patients $(10.6 \pm 18.2$ cells $)$ compared with healthy donors $(40.5 \pm 36.1$ cells $)$. Comparison of median values between different groups was performed using the Mann-Whitney U test. (B) Plasma sCD1d protein levels correlated with the number of NKT cells in PBMCs $\left(r^{2}=0.061\right)$. Comparison of median values between different groups was performed using Spearman's rank correlation.

RA patients had significantly fewer NKT cells ( $10.6 \pm 18.2$ cells $)$ than healthy controls (40.5 \pm 36.1 cells) (Fig. 3A). Interestingly, the plasma levels of sCD1d protein correlated significantly with the number of NKT cells in peripheral blood, as we reported previously (20) (Fig. 3B). This result suggests that sCD1d stimulates and activates NKT cells.

$\alpha$-GalCer-bound sCDId protein stimulates TCR Va24+ $V \beta 11^{+} N K T$ cells. To determine the functional significance of sCD1d, NKT cells were incubated with sCD1d and cytokine production was measured. NKT cells from healthy donors were expanded using $\alpha$-GalCer (Fig. 4A), and then sorted to isolate TCR V $\alpha 24^{+} \mathrm{VB} 11^{+} \mathrm{NKT}$. These cells were then cultured in the presence of recombinant sCD1d protein plus $\alpha$-GalCer, or plate-bound CD1d dimer XI plus $\alpha$-GalCer as a control. After incubation for $72 \mathrm{~h}$, secreted IFN- $\gamma, \mathrm{IL}-4$ and IL-10 were 
A

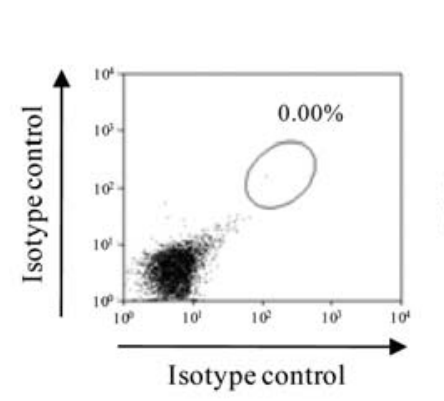

B
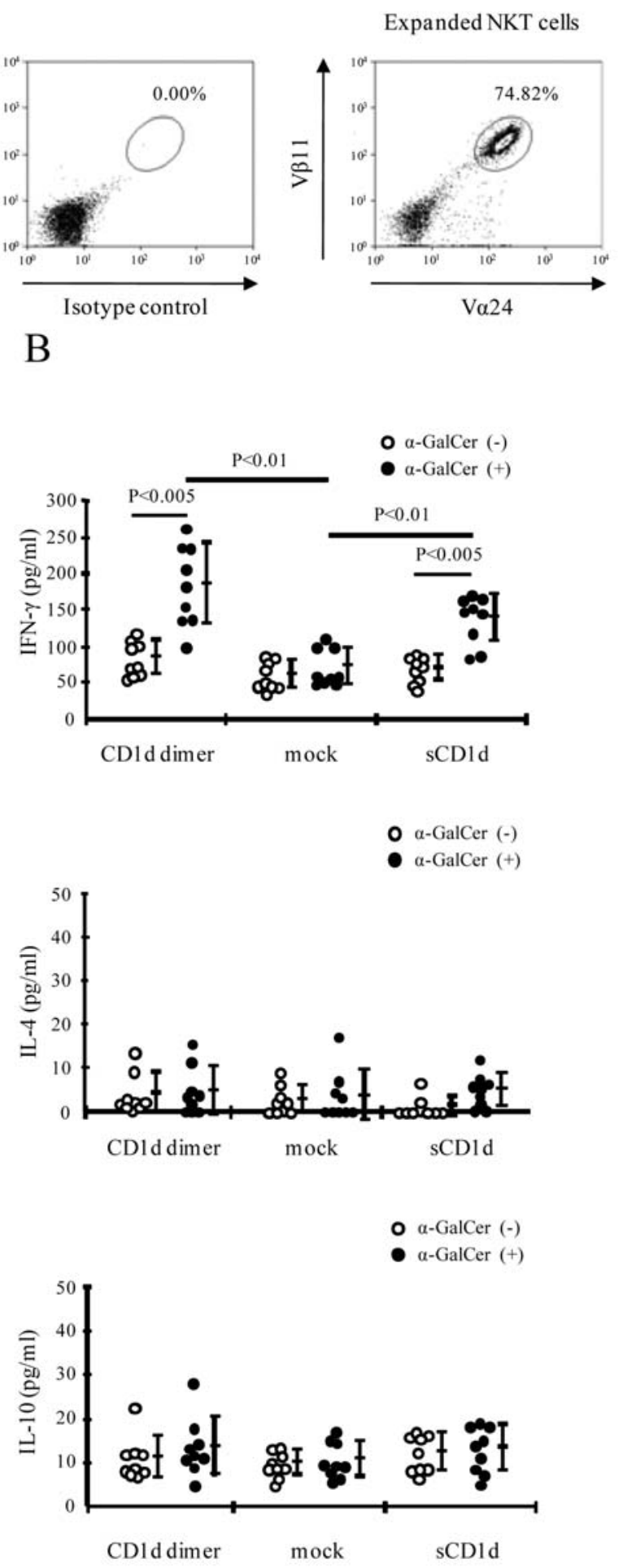

Figure 4. Stimulation of $\mathrm{V} \alpha 24^{+} \mathrm{V} B 11^{+}$NKT cells by sCD1d protein. (A) NKT cells from healthy donors were expanded as described in Materials and methods. Expanded NKT cells were stained with FITC-labeled anti-TCR Va24 mAb, PE-labeled anti-TCR Vß11 mAb, APC-labeled anti-CD3 mAb, and FITC + PE-labeled isotype control Ab. Values are the percentage of cells relative to the gated $\mathrm{CD}^{+}$cell population. (B) NKT cells from healthy donors $(n=9)$ were expanded and sorted $\left(C D 3^{+} \mathrm{V} \alpha 24^{+} \mathrm{VB1} 11^{+}\right)$. Sorted NKT cells were stimulated by plate-bound CD1d dimer XI, mock proteins, or sCD1d proteins with $(\bullet)$ and without $(\circ) \alpha$-GalCer. IFN- $\gamma$, IL-4 and IL-10 were assayed in culture supernatants after $72 \mathrm{~h}$. The secretion of IFN- $\gamma$ was increased in the presence of sCD1d plus $\alpha$-GalCer. Comparison of median values between different groups was performed using Student's t-test. measured by ELISA. Secretion of IFN- $\gamma$ from NKT cells increased with sCD1d plus $\alpha$-GalCer $(138.5 \pm 33.1 \mathrm{pg} / \mathrm{ml})$ compared with mock protein plus $\alpha$-GalCer $(73.53 \pm 17.36 \mathrm{pg} / \mathrm{ml})$ $(\mathrm{p}<0.01)$ (Fig. 4B), whereas that of IL-4 and IL-10 did not (Fig. 4B).

\section{Discussion}

Human NKT cells are thought to regulate immune tolerance or autoimmunity (17), with autoimmune disease patients showing significantly fewer NKT cells than healthy controls (18-20). However, the mechanisms by which these cell numbers are reduced remain unknown. The current study reveals significantly less sCD1d protein in the plasma of a group of RA patients compared with healthy donors. Considering the demonstrated relationship between sCD1d proteins and NKT cell numbers, these findings implicate a role for sCD1d in NKT cell activation.

Overexpression experiments demonstrated that the sCD1d protein was indeed secreted into the extracellular medium, even if without the B2-m binding domain. In support of this, others have shown CD1d expression on intestinal epithelial cells in $32-\mathrm{m}$-deficient mice (23).

The results obtained here also imply that sCD1d stimulates NKT cells, by combining NKT cells with recombinant sCD1d proteins and measuring cytokine production. NKT cells were stimulated to produce IFN- $\gamma$ in the presence of sCD1d mixed with lipids antigens $(\alpha$-GalCer). Previous studies $(24,25)$ demonstrated soluble HLA class I molecules (sHLAs) in sera from patients with RA, SLE, and multiple sclerosis. These soluble HLAs acted by binding to TCR on alloreactive T cells (26). It is therefore possible that SCD1d binds to TCR on NKT cells in vivo, stimulated by a natural ligand, and thus activates the NKT cells.

In an arthritis mouse model, Chiba et al (27) showed that in vivo activation of NKT cells using $\alpha$-GalCer inhibited collagen-induced arthritis (CIA). Another study (28) also demonstrated NKT cell activation in $\alpha$-GalCer-aggravated joint inflammation. The amount of lipid antigens present in these experiments were insufficient to suppress inflammations in the models used. The current study, however, strongly supports that the lipid antigens activated NKT cells not only via intact CD1d, but also via sCD1d in vivo. We speculate that the RA patients had decreased sCD1d protein secreted, resulting in reduced NKT cell numbers and thus activation.

\section{Acknowledgements}

We thank Dr F.G. Issa for a critical reading of the manuscript. This study was supported in part by the Grant-in-Aid for Scientific Research by the Japan Society for the Promotion of Science and the Japanese Ministry of Health, Labour and Welfare.

\section{References}

1. Martin LH, Calabi F and Milstein C: Isolation of CD1 genes: A family of major histocompatibility complex-related differentiation antigens. Proc Natl Acad Sci USA 83: 9154-9158, 1996.

2. Martin LH, Calabi F, Lefebvre FA, et al: Structure and expression of the human thymocyte antigens CD1a, CD1b, and CD1c. Proc Natl Acad Sci USA 84: 9189-9193, 1987. 
3. Balk SP, Bleicher PA and Terhost $\mathrm{C}$ : Isolation and characterization of cDNA and gene coding for a fourth CD1 molecule. Proc Nat Acad Sci USA 86: 252-256, 1989.

4. Albertson DG, Fishpool R, Sherrington P, et al: Sensitive and high resolution in situ hybridization to human chromosomes using biotin labeled probes: Assignment of the human thymocyte CD1 antigen genes to chromosome 1. EMBO J 7: 2801-2805, 1988.

5. Calabi F, Jarvis JM, Martin L, et al: Two classes of CD1 genes. Eur J Immunol 19: 285-292, 1989.

6. Procelli SA and Modlin RL: The CD1 system: antigen-presenting molecules for $\mathrm{T}$ cell recognition of lipids and glycolipids. Annu Rev Immunol 17: 297-329, 1999.

7. Amiot M, Bernard A, Raynal B, et al: Heterogeneity of the first cluster of differentiation: Characterization and epitopic mapping of three CD1 molecules on normal human thymus cells. J Immunol 136: 1752-1758, 1986.

8. Small TN, Knowles RW, Keever C, et al: M241 (CD1) expression on B lymphocytes. J Immunol 138: 2864-2868, 1987.

9. Delia D, Cattoreti G, Polli N, et al: CD1c but neither CD1a nor CD1b molecules are expressed on normal, activated, and malignant human B cells: Identification of a new B-cell subset. Blood 72: 241-247, 1988.

10. Blumberg RS, Terhorst C, Bleicher P, et al: Expression of a nonpolymorphic MHC class I-like molecule, CD1D, by human intestinal epithelial cells. J Immunol 147: 2518-2524, 1991.

11. Meunier L, Gonzalez-Romos A and Cooper KD: Heterogeneous populations of class II $\mathrm{MHC}^{+}$cells in human dermal cell suspensions. Identification of a small subset responsible for potent dermal antigen-presenting cell activity with features analogous to Langerhans cells. J Immunol 151: 4067-4080, 1993.

12. Canchis PW, Bhan AK, Landau SB, et al: Tissue distribution of the nonpolymorphic major histocompatibility complex class Ilike molecule, CD1d. Immunology 80: 561-565, 1993.

13. Lantz $\mathrm{O}$ and Bendelac $\mathrm{A}$ : An invariant $\mathrm{T}$ cell receptor alpha chain is used by a unique subset of major histocompatibility complex class I-specific CD4+ and CD4-8- $\mathrm{T}$ cells in mice and humans. J Exp Med 180: 1097-1106, 1994.

14. Yu KO, Im JS, Molano A, et al: Modulation of CD1d-restricted NKT cell responses by using $\mathrm{N}$-acyl variants of alphagalactosylceramide. Proc Natl Acad Sci USA 102: 3383-3388, 2005.

15. Yoshiga Y, Goto D, Segawa S, et al: Invariant NKT cells produce IL-17 through IL-23-dependent and -independent pathways with potential modulation of Th17 response in collagen-induced arthritis. Int J Mol Med 22: 369-374, 2008.
16. Coppieters K, Dewint P, Van Beneden K, et al: NKT cells: manipulable managers of joint inflammation. Rheumatology 46: 565-571, 2007.

17. Sandberg JK, Fast NM and Palacios EH: Selective loss of innate CD4+ Va24 natural killer T cells in human immunodeficiency virus infection. J Virol 76: 7528-7534, 2002.

18. Sumida T, Sakamoto A, Murata H, et al: Selective reduction of $\mathrm{T}$ cells bearing invariant $\mathrm{V}$ alpha $24 \mathrm{~J}$ alpha $\mathrm{Q}$ antigen receptor in patients with systemic sclerosis. J Exp Med 182: 1163-1168, 1995.

19. Wilson SB, Kent SC and Patton KT: Extreme Th1 bias of invariant Va24JaQ T cells in type 1 diabetes. Nature 391: 177-181, 1998.

20. Kojo S, Adachi Y, Keino H, et al: Dysfunction of T cell receptor AV24AJ18+BV11 ${ }^{+}$double negative regulatory natural killer $\mathrm{T}$ cells in autoimmune disease. Arthritis Rheum 44: 1127-1138, 2001.

21. Kojo S, Adachi Y, Tsutsumi A and Sumida T: Alternative splicing forms of the human CD1d gene in mononuclear cells. Biochem Biophys Res Commun 276: 107-111, 2000.

22. Kojo S, Tsutsumi A, Goto D and Sumida T: Low expression levels of soluble CD1d gene in patients with rheumatoid arthritis. J Rheumatol 30: 2524-2528, 2003.

23. Kim HS, Garcia J and Blumberg RS: Biochemical characterization of CD1d expression in the absence of beta2-microgloblin. J Biol Chem 274: 9289-9295, 1999.

24. Tsuchiya N, Shiota M, Yamaguchi A and Ito K: Elevated serum level of soluble HLA class I antigens in patients with systemic lupus erythematosis. Arthritis Rheum 39: 792-796, 1997.

25. Filaci G, Contini P and Brenci S: Soluble HLA class I and class II molecule levels in serum and cerebrospinal fluid of multiple sclerosis patients. Hum Immunol 54: 54-62, 1997.

26. Zavazava $\mathrm{N}$ and Kronke $\mathrm{M}$ : Soluble HLA class I molecules induce apoptosis in alloreactive cytotoxic T lymphocyte. Nat Med 2: 1005-1010, 1996.

27. Chiba A, Oki S, Miyamoto K, Hashimoto H, et al: Suppression of collagen-induced arthritis by natural killer $\mathrm{T}$ cell activation with OCH, a sphingosine-truncated analog of galactosylceramide. Arthritis Rheum 50: 305-313, 2004.

28. Kim HY, Kim HJ, Min HS, et al: NKT cells promote antibodyinduced joint inflammation by suppressing transforming growth factor 1 production. J Exp Med 201: 41-47, 2005. 